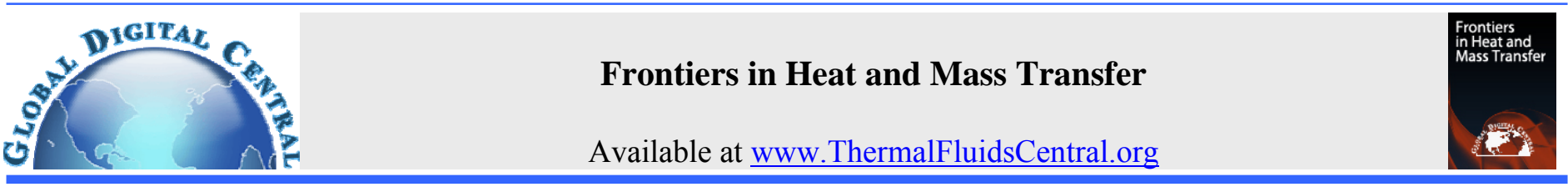

\title{
EXPERIMENTS ON HEAT TRANSFER CHARACTERISTICS OF SHEAR- DRIVEN LIQUID FILM IN CO-CURRENT GAS FLOW
}

\author{
Tomoki Hirokawa ${ }^{\mathrm{a}, *}$ Masahiko Murozono ${ }^{\mathrm{a}}$, Oleg Kabov ${ }^{\mathrm{b}, \mathrm{c}}$ and Haruhiko Ohta ${ }^{\mathrm{a}}$ \\ ${ }^{a}$ Department of Aeronautics and Astronautics, Kyushu University, Fukuoka, 813-0385, Japan \\ ${ }^{b}$ Institute of Thermophysics, Russian Academy of Science, Siberian branch, Novosibirsk, 630090, Russia \\ ${ }^{c}$ Tomsk Polytechnic University, Tomsk, 634050, Russia
}

\begin{abstract}
Experiments are performed to study the liquid film behavior and corresponding local heat transfer to shear-driven liquid film flow of water in the cocurrent nitrogen gas flow. The heated channel has a cross section of $30 \mathrm{~mm}$ in width and $5 \mathrm{~mm}$ in height, where the bottom is operated as a heating surface of $30 \mathrm{~mm}$ in width and $100 \mathrm{~mm}$ in length. The heated section is divided into segments to evaluate the local heat transfer coefficients. Under most gas Reynolds numbers, the local heat transfer coefficients are increased with increasing heat flux, where three mechanisms are important; (i) increase of areas along the three-phase interline around dried areas, (ii) rewetting of dried areas by the transverse liquid flow pushed by the generation of bubbles at the side edges of duct, (iii) microlayer evaporation during nucleate boiling in the film flow. The existence of duct corners makes the phenomena more unsteady and non-uniform in the transverse direction.
\end{abstract}

Keywords: Evaporation, Shear-driven liquid film, Heat transfer coefficient

\section{INTRODUCTION}

The density of dissipated heat from semiconductors tends to increase by the progress in electronic technology. The technical improvement is required for the existing thermal management systems using convective air or liquid. In recent years, the cooling systems utilizing phase change attract much attention for the cooling of power electronics in addition to the small semiconductor chips. In nucleate boiling and two-phase forced convection, the formation or the consumption of liquid film underneath bubbles and around the vapor core flow, respectively, becomes a key factor which determines the limitation of heat transfer. In such systems, however, the distribution and the behavior of liquidvapor interface cannot be controlled directly to satisfy the various cooling requirements but indirectly through the dynamic behaviors of the vapor phase. For usual cooling systems by forced convection of liquid, the location of heat generation is separated from that of final heat dissipation. In the proposed system, behaviors of liquid film flow are regulated by the interfacial shear stress exerted by the vapor flow, where multiple cooling units are combined to obtain the desired vapor velocities. To study the interaction between the phases under variable combinations of flow rates independent of heat flux level, the sheardriven liquid film flow is realized by the co-current gas flow of the component different from that of liquid in the present study.

The behavior and heat transfer in the liquid film e.g. liquid film falling down by gravity, evaporating meniscus and shear-driven liquid film have been investigated by a number of researchers. Kabov et al. (2002) investigated experimentally the heat transfer from a local heat source to a liquid film falling down by gravity along a vertical surface. Aqueous solution of $25 \%$ ethyl alcohol was used as a working fluid. Beyond the instability threshold, the existence of a thermocapillary counter flow produced a stagnation line of horseshoe shape at the upper edge, and the heat transfer was decreased with increasing film Reynolds number. Kabov and Chinnov (1997) investigated the same configuration by using a dielectric liquid, Perfluorine-triethyl-amine. The emergence of a horizontal wave was confirmed during the evaporation of subcooled liquid film at a threshold value of heat flux. At the downstream part of the wave, the film was divided into rivulets flowing down keeping certain horizontal distances. The distance was a function of liquid capillary constant and was depended weakly on the film Reynolds number. Lei et al. (2007, 2008 and 2009) investigated the formation and development of quasi-stable film structures in laminar wavy falling films by using IR-thermography. The heating surface was made of copper, where the length and the width of heater were $70 \mathrm{~mm}$ and $130 \mathrm{~mm}$, respectively. The test fluid was Polydimethylsiloxane. The results showed that waves along the transverse direction were appeared by Rayleigh-Taylor instability. They also investigated experimentally the development of thermal entry length and the heat transfer across laminar wavy falling films averaged over the entire heating length. They concluded that, at low Reynolds numbers, the thermal entry length agreed with the predicted ones by the correlation in the previous work and it deviated from the correlation with increasing Reynolds numbers and/or heat fluxes.

The heat transfer characteristics of a thin liquid film in a meniscus region are influenced by the capillary pressure and the disjoining pressure. Stephan et al. (1995) investigated a model describing the influence of capillary pressure on the evaporation of liquid film along a vertical plate. The numerical results were compared with the classical analytical solution by the Nusselt's film condensation theory. The deviation from the Nusselt theory became outstanding for thinner liquid film, which could be attributed to the ignored effect of capillary pressure on the distribution of the liquid film thickness. Wang et al. (2007) analytically investigated characteristics of heat and mass transfer from an evaporating meniscus in a two-dimensional micro-gap by using

\footnotetext{
* Corresponding author. Email: hirokawa@aero.kyushu-u.ac.jp
} 
the extended Young-Laplace model and kinetic theory-based expression for mass transport across the liquid-vapor interface. The contribution of the thin-film to the heat transfer was decreased with increasing channel size and/or wall superheat, and the importance of meniscus for the heat transfer was confirmed. They concluded that the capillary pressure played an important role for the determination of liquid film distribution along the meniscus. Du and Zhao (2012) proposed a conjugated heat transfer model for micro channels taking account of the interaction between the evaporating thin film in the contact line region and the heat conduction in the solid wall. High heat flux was confirmed in a narrow region of the evaporating thin film and in the corresponding region of the wall resulting in the existence of local minimal value of wall temperature. The apparent value of contact angle in the conjugated heat transfer model was smaller than that predicted by the model with a constant substrate temperature. Both of the peak and the total heat flow rates obtained by the conjugated heat transfer model was larger than those by the model of constant substrate temperature. Park et al. (2003) proposed a mathematical model of the flow and heat transfer characteristics for a thin film region in a micro-channel taking account of the gradient of vapor pressure and capillary force. They discussed the effects of channel height, heat fluxes and slip boundary conditions at the solid-liquid interface. The results indicated that the shape of the thin film in a microchannel was influenced by the gradient of vapor pressure. They also concluded that with increasing heat fluxes the length and the maximum thickness of the thin film decreased exponentially and the local evaporating mass flux increased linearly. The decrease of the channel height had little effect on the shape and thickness of the film. In the case of the slip condition, the length and film thickness of the thin film were decreased compared with those of the no-slip condition, and the decreased film thickness caused the increase of capillary and disjoining pressures. Park and Lee (2003) also proposed a model of the heat and mass transfer for the evaporation across the meniscus region in a two-dimensional micro-capillary channel. In the thin film region, extremely larger values of local heat transfer coefficient were reported, while the heat transfer rate was smaller than that in the meniscus region. Ibrahem et al. (2010) experimentally investigated the local heat flow at the three-phase contact line using a micro-scale temperature measurement technique (Höhmann and Stephan, 2002). The test section was composed of two vertical parallel flat plates to form a liquid-vapor meniscus due to capillary forces. The surface of inner wall was made by thin metallic foils employed as resistance heaters. The test fluid was HEF7100 evaporated between the plates under steady-state conditions. They observed two-dimensional microscale temperature fields on the back side of the heating foil by using an infrared camera with a spatial resolution of $14.8 \mu \mathrm{m} \times 14.8 \mu \mathrm{m}$. The local heat fluxes from the heater to the evaporating meniscus are calculated from the measured wall temperatures using an energy balance for each pixel element. The local heat fluxes at the contact line area were found to be about 5.4-6.5 times higher than the mean input heat fluxes at the foil. Kunkelmann et al. (2012) investigated experimentally and analytically the influence of three-phase contact line speed on the local heat transfer during the evaporation of the meniscus in the contact line region, where a peak of local heat transfer rate was observed. In the case of a receding contact line, the local peak was almost independent of its moving speed, while the heat transfer rate was significantly increased with increasing speed of advanced contact line.

Instability and rupture of liquid film causes the extension of dry patches and heat transfer crisis. Williams and Miles (1982) analyzed nonlinear effects on the liquid film rupture on a flat surface by using Navier-Stokes equations including a body force term describing the London-van-der-Waals dispersion forces. Ajaev et al. (2011, 2012) investigated the stability and the breakup of a thin liquid film on a solid surface with grooves located at regular intervals which were filled by gas under the action of disjoining pressure. Their mathematical model took the effect of slip along the menisci separating the air entrapped in the grooves from the liquid film flow, the effect of the deformation of

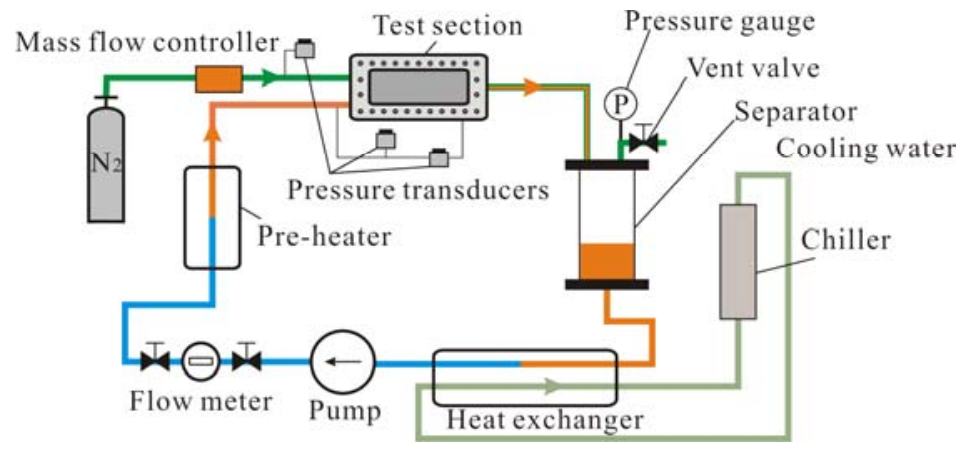

Fig. 1 Outline of test loop.

menisci due to local variations of pressure in the liquid film and the effect of the nonuniformities of the Hamaker constant into account. In the case of negligible variations of Hamaker constant, the effect of surface structure was destabilized compare to the results by the linear stability analysis for the flat plate. Numerical simulations in the strongly nonlinear regime indicated that the rupture time was decreased significantly due to the effect of grooves. They indicated the decrease of rupture time with increasing the ratio of the maximum and the minimum values of Hamaker constant.

Recently, the behavior and heat transfer characteristics of sheardriven liquid film in co-current gas flow have been investigated in detail. Liu and Kabov (2012) studied a two layer system consisting of a horizontal liquid layer contacting with its vapor. The Rayleigh instability and Marangoni instability were analyzed taking into account of the effects of buoyancy, thermocapillarity and interfacial shear forces and the evaporation of liquid. Kabov et al. (2007, 2011) investigated the flow of a locally heated liquid film moving under the shear force exerted by the gas flow. Water and FC72 were used as working liquids and air and nitrogen were used as gases. The critical heat flux by the formation of an initial stable dry patch in the liquid film was higher by several times than that for a vertical falling liquid film. The temperature distribution along the film surface was measured by the infrared scan. The thermocapillary tangential stress could exceed tangential shear stress caused by the friction of gas flow. Gatapova et al. $(2003,2004)$ and Gatapova and Kabov (2008) studied a two-dimensional model of steady laminar film flow and co-current gas flow along a horizontal plane wall of the channel with a heat source. An analytical solution for the temperature distribution in the locally heated liquid film was obtained for the linear velocity profile. A liquid bump caused by the thermocapillary force was obtained just above the heated zone. Kabova et al. $(2008,2009)$ investigated the thin non-isothermal liquid film flowing down by gravity and co-current gas flow in an inclined minichannel. They developed 3D time-dependent mathematical model. The effect of gravity as well as the effect of gas velocity was studied to define the features of film dynamics. They found that the gravity force had a significant effect on the film deformation. At lower gravity, 3D liquid film pattern was changed in the transverse direction and the generation of a middle wave between two lateral waves was observed, where the speed of film deformation became higher and the time required for the stabilization of flow became longer compared to those at normal gravity. Independent of gravity level, the increase of heat flux resulted in the emergence of liquid film deformation. Cheverda et al. (2013) investigated gas shear-driven rivulet flows in a minichannel with a height of $1.4 \mathrm{~mm}$ and a width of $30 \mathrm{~mm}$ under the variation of gravity levels. They reported the reduction of rivulet width with decreasing gravity level and its increase with increasing gas and/or liquid flow rates. Lyulin and Kabov (2014) experimentally investigated the evaporation rates and gas-liquid interfacial behaviors for the horizontal evaporating liquid layer under the existence of the shear-stress exerted by the gas flow. The test fluids were HFE-7100 for the liquid layer and nitrogen gas. The area of a square liquid reservoir was $50 \mathrm{~mm} \times 50 \mathrm{~mm}$, 


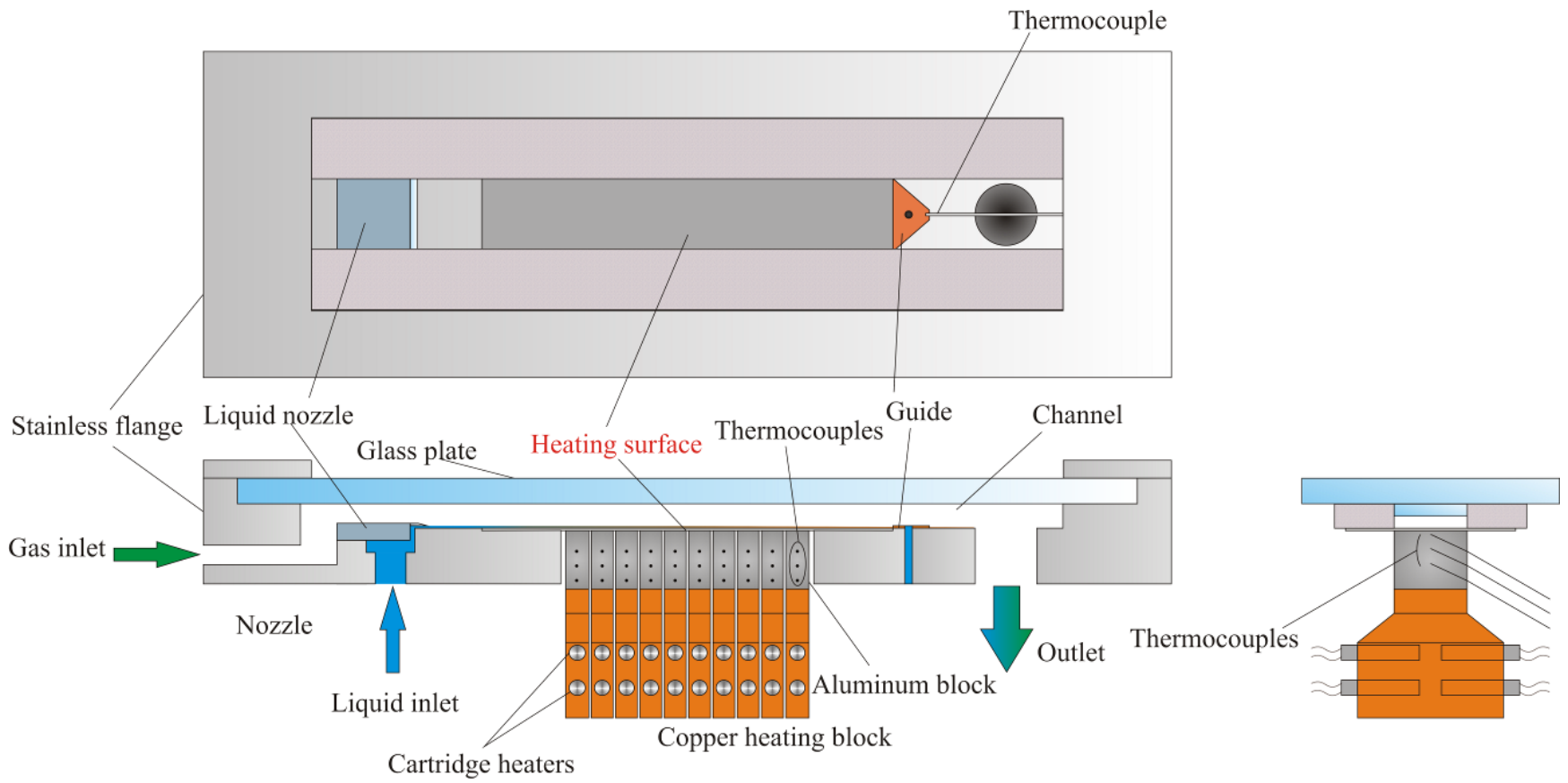

Fig. 2 Structure of test section.

and its depth was varied from 1.5 to $8 \mathrm{~mm}$. The results indicated that, with increasing gas and liquid temperatures from 20 to $40^{\circ} \mathrm{C}$, the depth for the local maximum of evaporation rate was shifted from 3 to $5 \mathrm{~mm}$. At the maximum evaporation flow rate, a stable and uniform convective flow induced by the thermocapillary force in the direction opposite to the gas flow was observed in the liquid layer. Houshmand and Peles (2013) investigated the heat transfer characteristics of a liquid film flow in a horizontal rectangular microchannel with a $1 \mathrm{~mm} \times$ $1 \mathrm{~mm}$ heater, where water is introduced from a $350 \mu \mathrm{m}$ circular hole to the gas stream of nitrogen. Considerable improvement of the heat transfer was observed in despite of no appreciable change in pressure drop compared to that for water flow without gas. At high heat fluxes, the heat transfer was enhanced at the location before the rupture of liquid film.

In the present study, to investigate the heat transfer during the evaporation and boiling of liquid film, the behaviors of film flow is varied by the interfacial shear stress exerted by the gas flow under different heat flux levels. To extend the ranges of flow rates of both phases, the two-component system is studied, where the gas flow rate is adjusted independently from the rate of film flow.

\section{EXPERIMENTAL APPARATUS}

Figure 1 shows the test loop composed of pump, flow meter, pre-heater, test section, separator and heat exchanger for the cooling of test liquid. Distilled water and nitrogen are selected as liquid and gas phases, respectively. The nitrogen gas is introduced directly to the test section by a mass flow controller. The test loop is always exposed to the atmosphere at the vent valve to exhaust nitrogen gas and evaporated water vapor in the downstream of the test section, and only liquid water is circulated again. To evaluate the performance of heat transfer, the gas temperature at the inlet and the liquid temperatures at the inlet and the outlet of test section are measured by K-type thermocouples inserted in the loop. The pressure drop across the test section is measured by pressure transducers.

Figure 2 shows the structure of test section assembled by an aluminum block with a heating surface, copper heating blocks, stainless steel flanges and a Pyrex glass plate for an observation window. The heated channel with a cross section of $30 \mathrm{~mm}$ in width and $5 \mathrm{~mm}$ in height is located horizontally. The top surface of the aluminum block is used as a heating surface with an area of $30 \mathrm{~mm}$ in width and $100 \mathrm{~mm}$ in length. Its bottom surface is contacted with copper heating blocks, where cartridge heaters are inserted at lower parts in order to supply heat flux by heat conduction. The heating assembly is divided into 10 segments along the flow direction as shown in the figure. They are thermally isolated each other by the gaps between the heated segments except the top part with a small thickness just beneath the heating surface. The segment structure makes possible the measurement of heat transfer data in the upstream location of the heating surface even under the conditions of dryout in the downstream by switching off a part of cartridge heaters. In addition, the evaluation of local heat transfer along the flow direction becomes possible. The liquid flow is introduced from the bottom of the test section by a nozzle of thin slit. The nozzle height $h_{N}$ is $1.0 \mathrm{~mm}$, whereas the overall height of the test section $H$ is $5.0 \mathrm{~mm}$. In each segment of aluminum block, 3 thermocouples are inserted at the depths of $1.5 \mathrm{~mm}, 7.5 \mathrm{~mm}$ and $13.5 \mathrm{~mm}$ from the heating surface to evaluate local heat fluxes and local surface temperatures from the temperature gradients. At the outlet, a guide plate concentrating liquid film flow is located to measure the mean liquid film temperature by using a thermocouple. Experiments are conducted under the atmospheric pressure. Gas flow rate is varied as a parameter keeping the liquid flow rate constant. The gas Reynolds number defined by the superficial gas velocity and the hydraulic diameter is varied from 0 to 3175 , and the film Reynolds number is fixed at 27.6. Both temperatures of subcooled liquid and gas flow at the inlet of the test section is kept at $25^{\circ} \mathrm{C}$. For the detailed observation of liquid film flow, images of top view are recorded by using a high-speed video camera through the glass plate. Experimental conditions are shown in Table 1.

Table 1 Experimental conditions

\begin{tabular}{clc}
\hline Channel height & $H$ & $5 \mathrm{~mm}$ \\
Nozzle height & $h_{N}$ & $1 \mathrm{~mm}$ \\
Test section outlet pressure & $P_{\text {out }}$ & $1 \mathrm{~atm}$ \\
Gas inlet temperature & $T_{g, \text { in }}$ & $25^{\circ} \mathrm{C}$ \\
Liquid inlet temperature & $T_{l, \text { in }}$ & $25^{\circ} \mathrm{C}$ \\
Liquid film Reynolds number & $\operatorname{Re}_{l}$ & 27.6 \\
Gas Reynolds number & $\operatorname{Re}_{g}$ & $0-3175$ \\
Heat flux & $q$ & $0-280 \mathrm{~kW} / \mathrm{m}^{2}$ \\
\hline
\end{tabular}




\section{DATA PROCESSING}

A local heat transfer coefficient is defined by

$$
\alpha_{i}=\frac{q_{i}}{T_{w, i}-T_{l, i}}
$$

where $\alpha_{i}$ : local heat transfer coefficient, $q_{i}$ : local heat flux, $T_{w, i}$ local surface temperature, $T_{l, i}$ : local mean fluid temperature at each segment. The local heat fluxes and the local surface temperatures are evaluated from the linear approximation of temperatures indicated by three thermocouples inserted in the aluminum block at different depth. The local liquid temperature is evaluated by the following procedure. The heat loss from the liquid film to the gas flow at the unheated section located upstream of the heating surface cannot be negligible under the conditions of a large difference between the inlet temperatures of liquid film and gas flows. An unheated preliminary experiment is performed at the same inlet liquid and gas temperatures and gas and liquid film Reynolds numbers as those for the heated experiments. By the temperature gradient of liquid film along the flow direction obtained from the unheated experiment, the liquid film temperature at the $1 \mathrm{st}$ segment is evaluated during the heated experiments. On the other hand, the liquid film temperature at the 10th segment is equated to the temperature of liquid film at the outlet of the test section. The liquid film temperatures from the 2 nd to 9 th segments are evaluated by the linear interpolation of the temperatures at the 1 st and 10th segments.

All of the measurement systems are carefully calibrated. The uncertainty in temperature is $\pm 0.25 \mathrm{~K}$, in pressure measurement $\pm 0.26 \mathrm{kPa}$, in liquid flow rate $\pm 1 \%$ and in gas flow rate $\pm 1.2 \mathrm{l} / \mathrm{min}$ even at the minimum experimental value of $20 \mathrm{l} / \mathrm{min}$.

\section{EXPERIMENTAL RESULTS AND DISCUSSION}

Figures 3(a)-(c) show liquid film behaviors and its rupture for the different gas Reynolds numbers of 0 (no gas flow), 1270 and 3175 at the liquid inlet temperature $25^{\circ} \mathrm{C}$ and heat flux $50 \mathrm{~kW} / \mathrm{m}^{2}$. In all experiments described here, the film Reynolds number is kept at 27.6. At gas Reynolds number 0, i.e. no shear stress on the surface of the liquid film flow, bubbles of dissolved air but not of evaporated vapor are observed along the heating surface. At gas Reynolds number 1270 , the rupture of liquid film is initiated at the center of the transverse direction in the downstream of the heating surface. With increasing gas Reynolds number, the dried area is expanded toward the upstream (cf. Figs.3 (b), (c)). The rupture is promoted by two reasons. The increased interfacial shear stress exerted by the gas flow with higher velocity makes the liquid film thinner. In addition, toward the side edges of the duct by the formation of meniscus, the pressure difference between the gas and liquid is increased, i.e. the liquid pressure is decreased, and the liquid film is squeezed into the side edges. The dried area is initiated in the downstream because the liquid film thickness becomes thinner by the evaporation. Surface temperature distribution and local heat transfer coefficient at heat flux 50kW/ $/ \mathrm{m}^{2}$ are shown in Figs. 3(d) and (e), where the data for both of the 1st and the 10th segments are omitted because of larger heat losses to the flanges surrounding the heating surface. At gas Reynolds number 1270, the local heat transfer coefficient is larger than those for other gas Reynolds numbers in all segments because of the enhanced evaporation by the reduced liquid film thickness. At gas Reynolds numbers larger than 1270, heat transfer deterioration occurs owing to the excessive disappearance of liquid film promoting the large extension of dried area, where lower heat transfer coefficients are obtained for higher gas Reynolds number.

Figures 4(a)-(c) show liquid film behaviors at heat flux $150 \mathrm{~kW} / \mathrm{m}^{2}$. At gas Reynolds number 0, nucleate boiling occurs in the downstream, but no dried area is observed on the entire heating surface. At gas Reynolds number 1270, the liquid film rupture occurs and the dried area is observed for all segments of the heating surface. The oscillatory behaviors of the rewetting and drying in the transverse direction on the latter half part of the heating surface from 5th to 10th segment occurs along the following mechanism. The growth of bubbles due to nucleate boiling at the side edges of the heating surface, i.e. the side edges of the duct, pushes the liquid film towards the transverse direction and rewets the dried area extended in the center of the heating surface. At the instance of the rewetting, the evaporation is enhanced and the surface temperature is decreased resulting in the suppression of nucleate boiling at the side edges. Again a dried area is extended in the center of the heating surface increasing the surface temperature and nucleate boiling is initiated. With increasing gas Reynolds number, the iteration of drying and rewetting is still observed in the midstream of the heating surface. However, the liquid film flowing along the side edges of the heating surface is accelerated towards the downstream by the enhanced shear stress, and finally at gas Reynolds number 3175, the coalescence of squeezed liquid films from the side edges occurs. At the unheated section connected to the downstream edge of the heating surface, the extension of dried area is observed. This is because there is no force to push the liquid film towards the center of the heating surface under no generation of bubbles at the side edges of the duct. Figures 4(d) and (e) show surface temperature and local heat transfer coefficient respectively at heat flux $150 \mathrm{~kW} / \mathrm{m}^{2}$. The heat transfer coefficient for no gas flow is the highest because of no emergence of dried area on the entire heating surface. The heat transfer coefficient becomes larger along the flow direction with decreasing liquid film thickness. With gas flows, on the other hand, the heat transfer coefficients are smaller than the value without gas flow owing to the periodical emergence of dried area in the center of transverse direction. Also in this case, the decrease of film thickness due to the evaporation and increased gas flow rate containing the evaporated vapor increases the heat transfer coefficient along the flow direction. The heat transfer coefficient tends to decrease at higher gas Reynolds number by the excessive extension of the dried area.

Figures 5(a)-(c) show liquid film behaviors at heat flux $250 \mathrm{~kW} / \mathrm{m}^{2}$. Under no gas flow, no rupture of liquid film is observed and nucleate boiling occurs as observed at heat flux $150 \mathrm{~kW} / \mathrm{m}^{2}$. At gas Reynolds numbers larger than 1270 , liquid films from the side edges of duct are coalesced, which is similar to the case of $150 \mathrm{~kW} / \mathrm{m}^{2}$. And also two dried areas emerge on the upstream part of the heating surface and on the downstream unheated section. With increasing gas Reynolds number up to 3175 , the dried area on the heating surface are extended widely because of further reduction of liquid film thickness and enhancement of evaporation. The surface temperature distribution and local heat transfer coefficient are shown in Figs. 5(d) and (e). Without gas flow, the surface temperature in the upstream part of the heating surface becomes higher because of the boiling with smaller nucleation site densities in subcooled liquid. In the flow direction, the surface temperature decreases with increasing liquid temperature on the upstream part of the heating surface. On the other hand, at gas Reynolds numbers larger than 1270, the extension of dried area is already observed on the upstream part of the heating surface and the surface temperatures become higher at larger gas Reynolds number. The surface temperature is decreased in the flow direction due to the iteration of rewetting by the liquid film pushed towards transvers direction by the generation of bubbles at the side edges of the duct. In the midstream of the heating surface, the coalescence of liquid films from the side edges occurs and three-phase interlines disappear resulting in the slight increase of surface temperature independent of gas Reynolds numbers including the case of no gas flow. In the downstream of the heating surface, the liquid film covering the entire width of the heating surface becomes thinner due to the evaporation resulting in the acceleration of gas flow rate, and the surface temperatures decrease again. In the case of no gas flow, however, the surface temperature increases in the downstream of the heating surface, which seems to be caused by the emergence of small dried areas, however, not clearly observed. In despite of complicated behaviors of surface temperatures along the flow direction, the heat transfer 

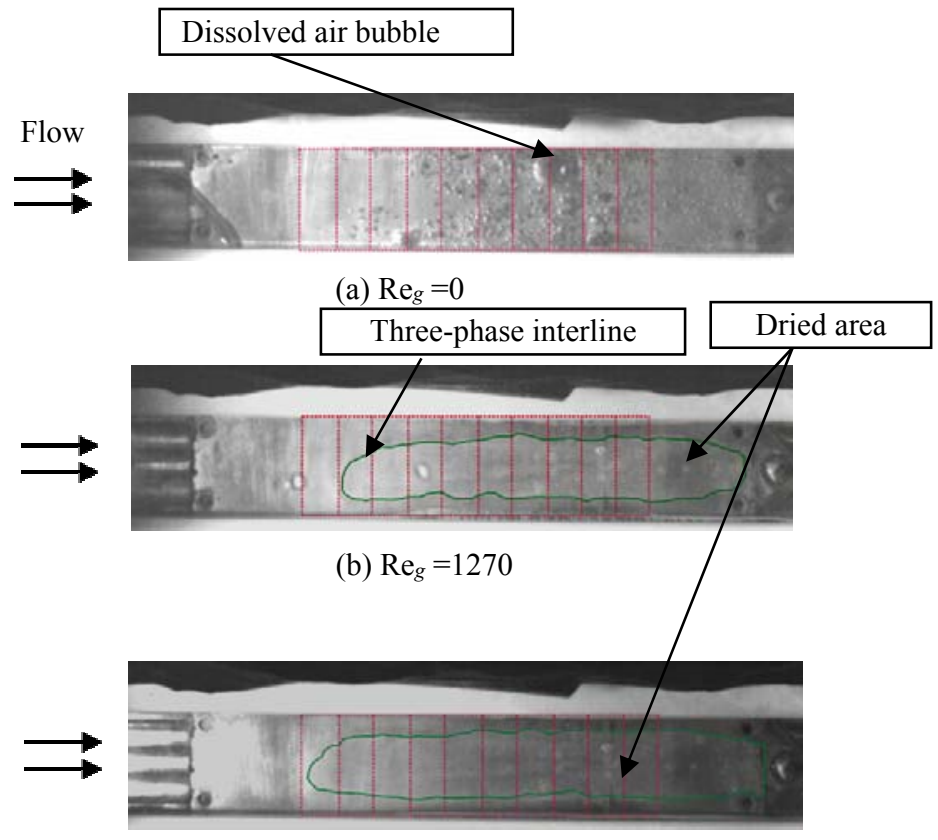

(c) $\operatorname{Re}_{g}=3175$

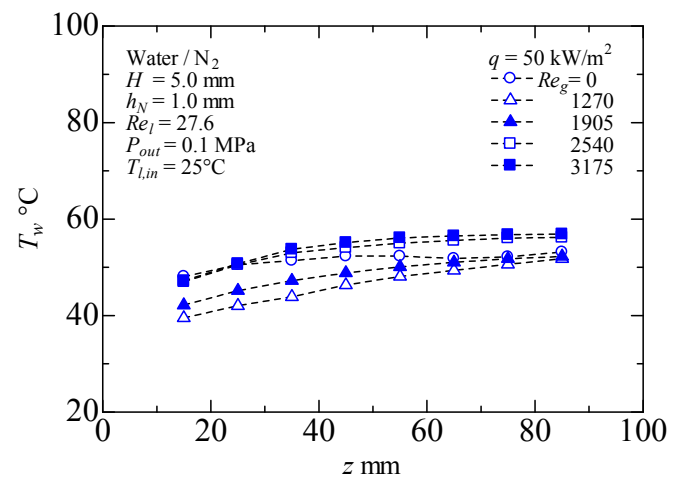

(d) Surface temperature distribution

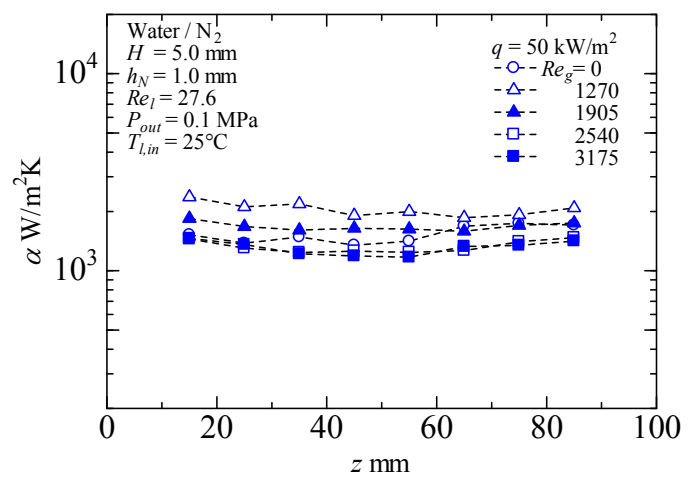

(e) Local heat transfer coefficient

Fig. 3 Liquid film behavior, surface temperature distribution and local heat transfer at $q=50 \mathrm{~kW} / \mathrm{m}^{2}$.

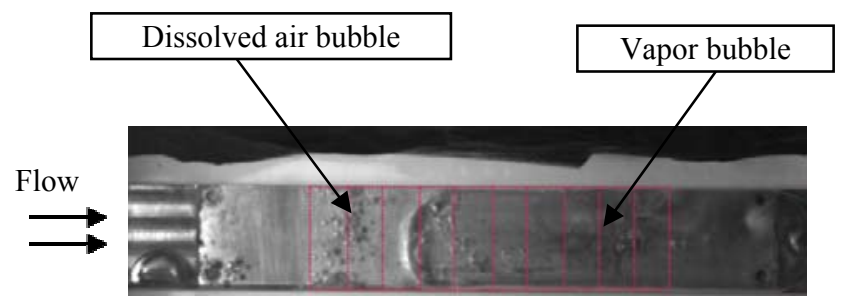

(a) $\operatorname{Re}_{g}=0$

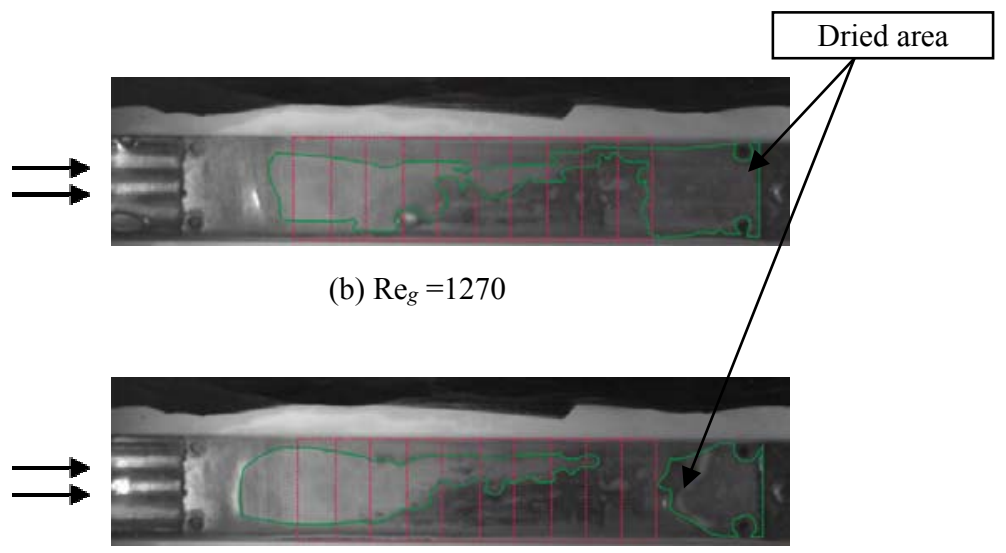

(c) $\operatorname{Re}_{g}=3175$

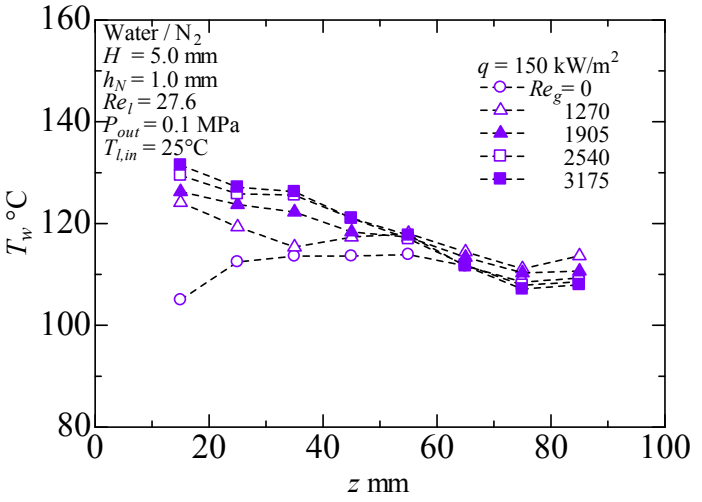

(d) Surface temperature distribution

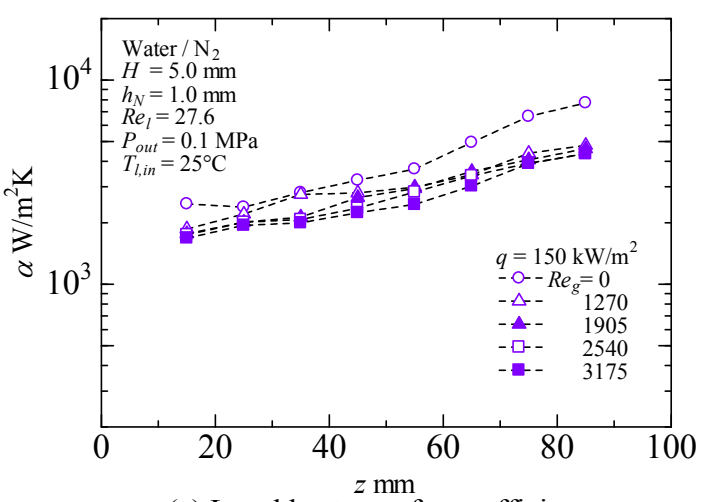

(e) Local heat transfer coefficient

Fig. 4 Liquid film behavior, surface temperature distribution and local heat transfer at $q=150 \mathrm{~kW} / \mathrm{m}^{2}$. 

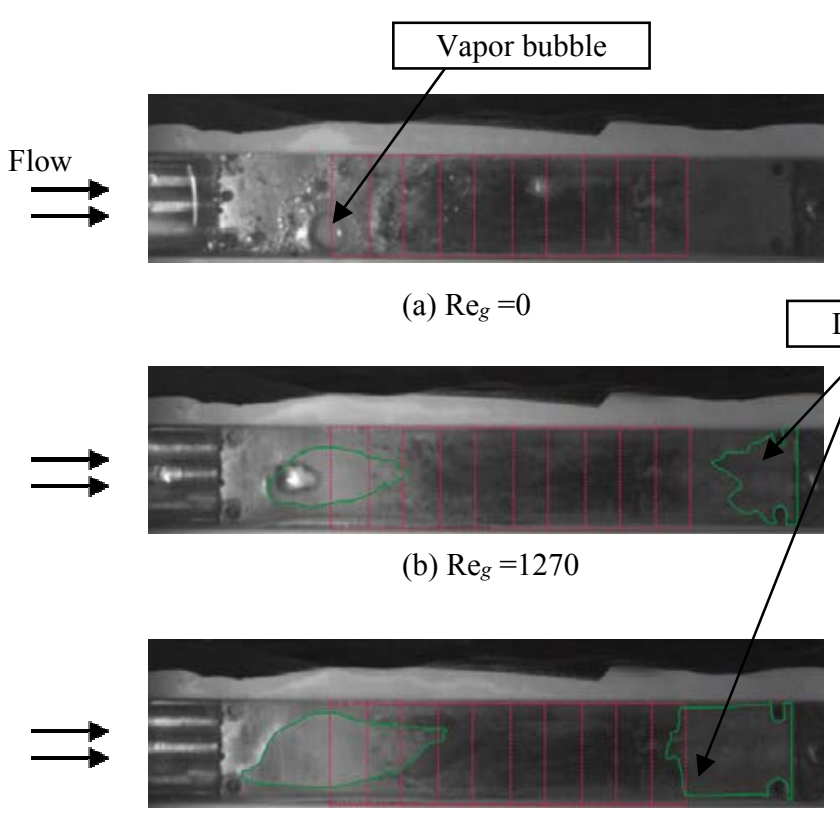

(c) $\operatorname{Re}_{g}=3175$

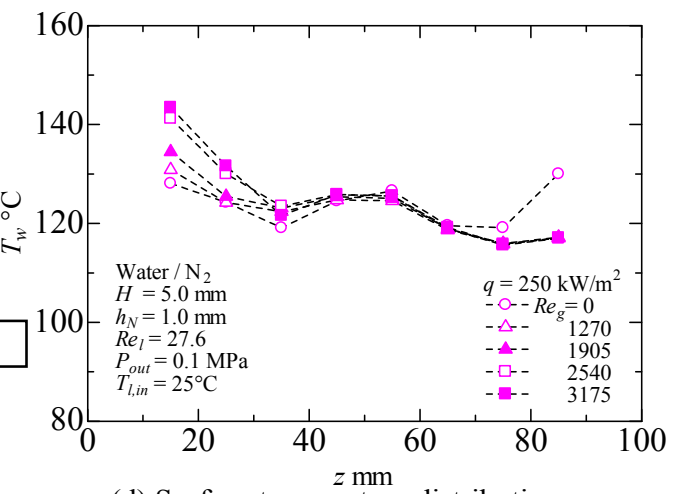

(d) Surface temperature distribution

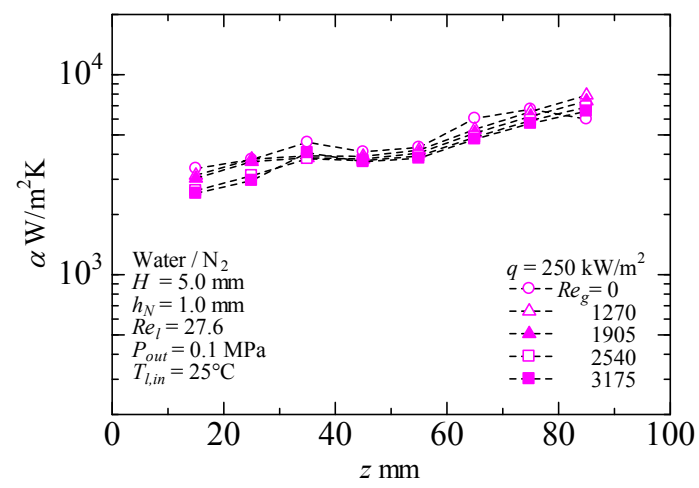

(e) Local heat transfer coefficient

Fig. 5 Liquid film behavior, surface temperature distribution and local heat transfer at $q=250 \mathrm{~kW} / \mathrm{m}^{2}$.

coefficients increase almost monotonously towards the downstream for all gas Reynolds numbers including the case of no gas flow. The variation in the levels of heat transfer coefficient with Reynolds number is quite small compared with the case of $150 \mathrm{~kW} / \mathrm{m}^{2}$, which implies that the liquid-vapor behaviors are dominated not by the gas flow rate but by the elevated heat flux via the phenomena such as the extension of dried area, the generation of bubbles and the generation of vapor due to enhanced evaporation. Figures 6 (a)-(c) show the liquid film behaviors and corresponding values of local heat transfer coefficients under the combinations of gas Reynolds number and heat flux for the 2nd, 5th and 9th segments, respectively. The liquid film behaviors along the center line of the heating surface are classified into the following patterns, i.e. film flow without nucleate boiling $(\bullet)$ or with nucleate boiling $(\boldsymbol{\Delta})$, oscillation of drying and rewetting $(\Delta)$, rupture and extension of dried area without rewetting $(\circ)$. For all of three locations, dryout accompanied by the temperature excursion (represented by white areas) was observed at heat flux larger than $300 \mathrm{~kW} / \mathrm{m}^{2}$ and no heat transfer data was acquired. In Fig. 6(a), (a-i) the film flow without rupture $(\bullet \boldsymbol{\Delta})$ is observed for either of no gas flow or of the lowest heat flux, where no interfacial shear stress or almost no evaporation to reduce the film thickness. (a-ii)Subcooled nucleate boiling $(\boldsymbol{\Delta})$ starts at high heat flux under no gas flow and the rapture of liquid film (O) occurs at high gas Reynolds number under the smallest heat flux. (a-iii) For the other combinations of gas Reynolds number and heat flux, liquid film behaviors are not influenced by gas Reynolds number but only by heat flux level, where the rupture of liquid film (O) turns to the iteration of extending dried area and its rewetting $(\Delta)$ with increasing heat flux. (a-iv) Further increase of heat flux results in $\mathrm{CHF}$ conditions accompanied by the rapid temperature rise (indicated by white area). It seems to be a contradictory trend that the rupture of liquid film occurred at low heat flux becomes periodically rewetted with increasing heat flux. Increase of heat flux promotes the nucleation of bubbles along the side edges of the duct, where a plenty of liquid is still flowing forming menisci. The generation of bubbles pushes the liquid accumulated along the side edges of the duct towards the center and the dried area is rewetted periodically synchronized by the bubble generation. (a-v) Local heat transfer coefficients become larger when the drying and rewetting are iterated at higher heat fluxes up to CHF values at around $300 \mathrm{~kW} / \mathrm{m}^{2}$. (a-vi) Furthermore, lower gas Reynolds number or zero gas flow tends to increase the heat transfer coefficient, where the ratio of the area along three-phase interlines to the dried area becomes larger. In Fig.6(b) for 5th segment, (b-i) the film flow without rupture $(\bullet \boldsymbol{\Delta})$ is still observed for either of no gas flow or of the lowest heat flux. Because of the reduction of liquid subcooling from the value of 2nd segment, nucleate boiling ( $\boldsymbol{\Delta})$ starts at lower heat flux for no gas flow. (b-ii) Because the rupture of the liquid film extends from the downstream to the upstream on the heating surface with increasing heat flux, the rapture ( $\circ$ ) occurs at lower gas Reynolds number at this location under the smallest heat flux. (b-iii) For the other combinations of gas Reynolds number and heat flux, with increasing heat flux up to $\mathrm{CHF}$ values, the rupture of liquid film (o) turns to the extension of dried area and its rewetting $(\Delta)$ and finally to the liquid film flow without rupture but with nucleation of bubbles. The transition is realized by the liquid supply from the side edges of the duct by the nucleation of bubbles there. (b-iv) Heat transfer coefficients at 5th segment become larger than those at 2 nd segment at the same heat flux level. The increase of heat transfer at high heat flux is caused by the enhanced nucleate boiling at smaller liquid subcooling. Beneath the bubbles, there are microlayers with liquid film thickness far smaller than the thickness of the film flowing in the duct. The trends (b-i)-(biv) are more emphasized at 9th segment by the further reduction of liquid subcooling or by zero subcooling, i.e. saturated, depending on the conditions.

\section{CONCLUSIONS}

To investigate the performance of cooling system by the evaporation of thin liquid film, the behaviors of liquid film and heat transfer characteristics of co-current gas and liquid film flow were studied experimentally by the independent control of both flow rates. 


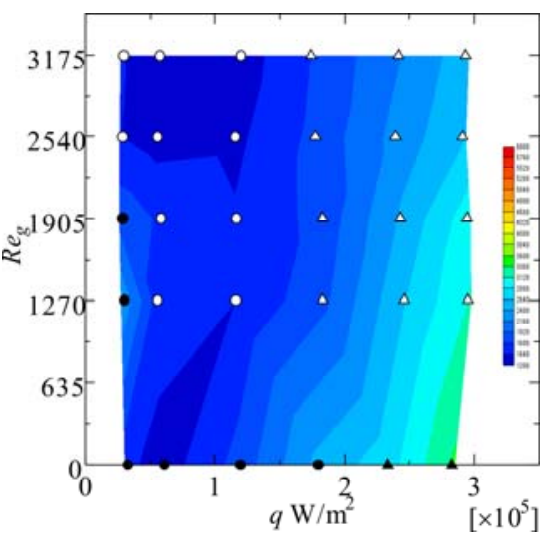

(a) Upstream (2nd)

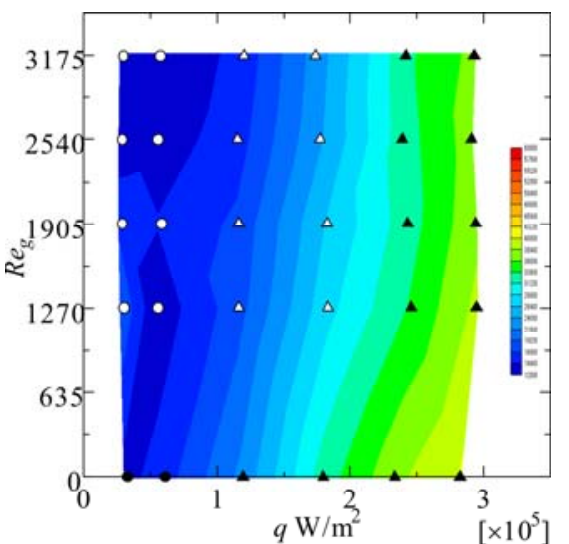

(b) Midstream (5th)
- Film flow without nucleate boiling

- Film flow with nucleate boiling

$\triangle$ Oscillation of drying and rewetting

$\circ$ Rupture and extension of dried area without rewetting

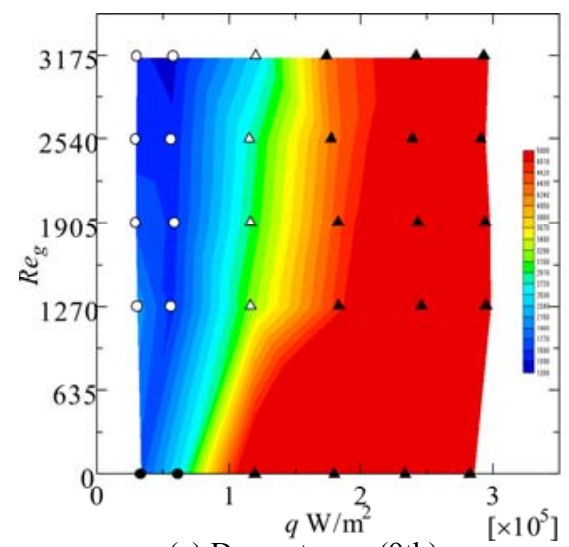

(c) Downstream (9th)

Fig. 6 Liquid film behavior and local heat transfer coefficient at $T_{l, i n}=25^{\circ} \mathrm{C}$.

Experiments were performed by using water and nitrogen gas under the atmospheric pressure. Liquid film Reynolds number was fixed at 27.6, while gas Reynolds number was varied from 0 to 3175 . The heat flux was increased up to $300 \mathrm{~kW} / \mathrm{m}^{2}$. The followings were clarified.

1. Local heat transfer corresponding to the behaviors of liquid film especially of its rupture along the flow direction were clarified by the heating surface with the devised segment structure.

2. Liquid film behaviors along the center line of the heating surface were classified into four patterns; film flow without nucleate boiling or with nucleate boiling, iteration of drying and rewetting, rupture and extension of dried area without rewetting.

3. In low heat flux region, for all gas Reynolds numbers including the case of no gas flow, the local heat transfer coefficients were increased at higher heat flux because of larger extension of areas influenced by the three-phase interlines.

4. In high heat flux region, with increasing heat flux, local heat transfer coefficients were also increased not by the uniform reduction of liquid film thickness due to enhanced evaporation but by the iterated rewetting of dried area. The rewetting was promoted at higher heat flux where liquid supply from the side edges of duct was enhanced pushed by the bubble generation there. By further increase of heat flux results in nucleation of bubbles from the center of heating surface and the local heat transfer coefficients became higher by the evaporation of microlayer which was far thinner than the thickness of flowing liquid film.

5. For most combinations of gas Reynolds number and heat flux, local heat transfer coefficients were decreased with increasing gas Reynolds number because of the liquid film rupture and the extension of dried area by the excessive interfacial shear stress exerted by the gas flow.

It was clarified that the behaviors of liquid film and corresponding heat transfer were strongly influenced by the existence of duct corners and the phenomena became more unsteady or periodical and not uniform in the transverse direction perpendicular to the flow.

\section{ACKNOWLEDGEMENTS}

We gratefully acknowledge the support by the Ministry of Education and Science of Russia (Project identifier RFMEFI61314X0011).

\section{NOMENCLATURE}

$\begin{array}{ll}h_{N} & \text { Nozzle height }(\mathrm{m}) \\ H & \text { Channel height }(\mathrm{m}) \\ P & \text { Pressure }(\mathrm{Pa}) \\ q & \text { Heat flux }\left(\mathrm{W} / \mathrm{m}^{2}\right) \\ \operatorname{Re} & \text { Reynolds number } \\ T & \text { Temperature }(\mathrm{K})\end{array}$

Greek Symbols

$\alpha \quad$ Heat transfer coefficient $\left(\mathrm{W} / \mathrm{m}^{2} \mathrm{~K}\right)$

$\begin{array}{ll}\text { Subscripts } & \\ g & \text { Gas } \\ \text { in } & \text { Inlet } \\ l & \text { Liquid } \\ \text { out } & \text { Outlet }\end{array}$

\section{REFERENCES}

Ajaev, V.S., Gatapova, E.Y., and Kabov, O.A., 2011, "Rupture of Thin Liquid Films on Structured Surfaces," Physical Review E., 84, 041606. http://dx.doi.org/10.1103/PhysRevE.84.041606

Ajaev, V.S., Gatapova, E.Y., and Kabov, O.A., 2012, "Stability of a Liquid Film on a Surface with Periodic Array of Gas-filled Grooves," Microgravity Science and Technology, 24, 33-37. http://dx.doi.org/10.1007/s12217-011-9288-z

Cheverda, V.V., Glushchuk, A., Queeckers, P., Chikov, S.B., and Kabov, O.A., 2013, "Liquid Rivulets Moved by Shear Stress of Gas Flow at Altered Levels of Gravity," Microgravity Science and Technology, 25, 73-81.

http://dx.doi.org/10.1007/s12217-012-9335-4

Du, S.Y., and Zhao, Y.H., 2012, "Numerical Study of Conjugated Heat Transfer in Evaporating Thin-films near the Contact Line," International Heat and Mass Transfer, 55, 61-68. http://dx.doi.org/10.1016/i.ijheatmasstransfer.2011.08.039

Gatapova, E.Y., and Kabov, O.A., 2008, "Shear-driven Flows of Locally Heated Liquid Films," International Journal of Heat and Mass 
Transfer, 51, 4794-4810.

http://dx.doi.org/10.1016/j.ijheatmasstransfer.2008.02.038

Gatapova, E.Y., Kabov, O.A., and Marchuk, I.V., 2004, "Thermocapillary Deformation of a Locally Heated Liquid Film Moving under the Action of a Gas Flow," Technical Physics Letters, 30, 418-421.

http://dx.doi.org/10.1134/1.1760873

Gatapova, E.Y., Lyulin, Y.V., Marchuk, I.V., Kabov, O.A., and Legros, J.C., 2003, "The Thermocapillary Convection in Locally Heated Laminar Liquid Film Flow Caused by Co-current Gas Flow in Narrow Channel," International Conference on Microchannels and Minichannels, 1, 457-465.

http://dx.doi.org/10.1115/ICMM2003-1055

Höhmann, C., and Stephan, P., 2002, "Microscale Temperature Measurement at an Evaporating Liquid Meniscus," Experimental Thermal and Fluid Science, 26, 157-162.

http://dx.doi.org/10.1016/S0894-1777(02)00122-X

Houshmand, F., and Peles, Y., "Convective Heat Transfer to Sheardriven Liquid Film Flow in a Microchannel," International Journal of Heat and Mass Transfer, 64, 42-52.

http://dx.doi.org/10.1016/j.ijheatmasstransfer.2013.04.012

Ibrahem, K., Rabbo, M.F.A., Roisman, T.G., and Stephan, P., 2010, "Experimental Investigation of Evaporative Heat Transfer Characteristics at the 3-phase Contact Line," Experimental Thermal and Fluid Science, 34, 1036-1041.

http://dx.doi.org/10.1016/j.expthermflusci.2010.02.014

Kabov, O.A., and Chinnov, E.A., 1997, "Heat Transfer from a Local Heat Source to a Subcooled Falling Liquid Film Evaporating in a Vapour-gas Medium," Russian Journal of Engineering Thermophysics, 7, 1-34.

Kabov, O.A., Lyulin, Y.V., Marchuk, I.V., and Zaitsev, D.V., 2007, "Locally Heated Shear-driven Liquid Films in Microchannels and Minichannels," International Journal of Heat and Fluid Flow, 28, 103112.

http://dx.doi.org/10.1016/j.ijheatfluidflow.2006.05.010

Kabov, O.A., Scheid, B., Sharina, I.A., and Legros, J.C., 2002, "Heat Transfer and Rivulet Structures Formation in a Falling Thin Liquid Film Locally Heated," International Journal of Thermal Sciences, 41, 664-672.

http://dx.doi.org/10.1016/S1290-0729(02)01361-3

Kabov, O.A., Zaitsev, D.V., Cheverda, V.V., and Bar-Cohen, A., 2011, "Evaporation and Flow Dynamics of Thin, Shear-driven Liquid Films in Microgap Channels," Experimental Thermal and Fluid Science, 35, $825-831$.

http://dx.doi.org/10.1016/j.expthermflusci.2010.08.001

Kabova, Y.O., Kuznetsov, V.V., and Kabov, O.A., 2008, "Gravity Effect on the Locally Heated Liquid Film Driven by Gas Flow in an Inclined Minichannel," Microgravity Science and Technology, 20, 187192.

http://dx.doi.org/10.1007/s12217-008-9032-5

Kabova, O.Y., Kuznetsov, V.V., and Kabov, O.A., 2009, “The Effect of Gravity and Shear Stress on a Liquid Film Driven in a Horizontal
Minichannel at Local Heating," Microgravity Science and Technology, 21, 145-152.

http://dx.doi.org/10.1007/s12217-009-9154-4

Kunkelmann, C., Ibrahem, K., Schweizer, N., Herbert, S., and Stephan, P., 2012, "The Effect of Three-phase Contact Line Speed on Local Evaporative Heat Transfer: Experimental and Numerical Investigations," International Journal of Heat and Mass Transfer, 55, 1896-1904.

http://dx.doi.org/10.1016/j.ijheatmasstransfer.2011.11.044

Lel, V., Stadler, H., Pavlenko, A., and Kneer, R., 2007, "Evolution of Metastable Quasi-regular Structures in Heated Wavy Liquid Films," Heat Mass Transfer, 43, 1121-1132.

http://dx.doi.org/10.1007/s00231-006-0187-6

Lel, V.V., Al-Sibai, F., Knner, R., 2009, "Thermal Entry Length and Heat Transfer Phenomena in Laminar Wavy Falling Films," Microgravity Science and Technology, 21, Suppl 1, S215-S220. http://dx.doi.org/10.1007/s12217-009-9141-9

Lel, V.V., Kellermann, A., Dietze, G., Kneer, R., and Pavlenko, A.N., 2008, "Investigations of the Marangoni Effect on the Regular Structures in Heated Wavy Liquid Films," Experimental Fluids, 44, 341-354.

http://dx.doi.org/10.1007/s00348-007-0408-x

Liu, R., and Kabov, O.A., 2012, "Instabilities in a Horizontal Liquid Layer in Cocurrent Gas Flow with an Evaporating Interface," Physical Review E, 85, 066305.

http://dx.doi.org/10.1103/PhysRevE.85.066305

Park, K., Noh, K.J., and Lee, K.S., 2003a, "Transport Phenomena in the Thin-film Region of a Micro-channel," International Journal of Heat and Mass Transfer, 46, 2381-2388. http://dx.doi.org/10.1016/S0017-9310(02)00541-0

Park, K., and Lee, K.S., 2003b, "Flow and Heat Transfer Characteristics of the Evaporating Extended Meniscus in a Microcapillary Channel," International Journal of Heat and Mass Transfer, 46, 4587-4594.

http://dx.doi.org/10.1016/S0017-9310(03)00306-5

Stephan, K., Zhong, L.-C., and Stephan, P., 1995, "Influence of Capillary Pressure on the Evaporation of Thin Liquid Films," Heat and Mass Transfer, 30, 467 - 472. http://dx.doi.org/10.1007/BF01647453

Lyulin, Y., and Kabov, O., 2014, "Evaporative Convection in a Horizontal Liquid Layer under Shear-stress Gas Flow," International Journal of Heat and Mass Transfer, 70, 599-609.

http://dx.doi.org/10.1016/j.ijheatmasstransfer.2013.11.039

Wang, H., Garimella, S.V., and Murthy, J.Y., 2007, "Characteristics of an Evaporating Thin Film in a Microchannel," International Journal of Heat and Mass Transfer, 50, 3933-3942. http://dx.doi.org/10.1016/j.ijheatmasstransfer.2007.01.052

Williams, M.B., and Davis, S.H., 1982, "Nonlinear Theory of Film Rupture," Journal of Colloid and Interface Science, 90, 1, 220-228. http://dx.doi.org/10.1016/0021-9797(82)90415-5 